\title{
Synergetic Effect of Lean and Green on Innovation: A Resource- based perspective
}

\begin{abstract}
The purpose of this study is twofold: to improve understanding on how the synergetic relationship between lean and green practices is operationalized and how innovative practices are fostered in workplace through integrated lean and green approaches. The Resource-based view (RBV) of the firm, and in particular, the concept of complementarity is used as a theoretical lens to achieve the purpose of the study. Following an inductive theory building approach using exploratory case study methodology in two manufacturing organizations in the UK, the authors conduct twelve semi-structured interviews with cross-functional team involved in integrated lean and green practices. The outcomes of the study evidence several examples of innovation fostered through synergetic lean and green implementation, though the integration requires customization depending upon the operations profile of selected cases, e.g. high volume/ low variety versus low volume and high variety setting. Our study also reported the possibility of creation of environmental value alongside economic value, e.g. eco-friendly products are cheaper to produce through integrated lean and green practices in design and service delivery processes. Cross-functional collaboration and collaboration with suppliers are key to promote innovation within operations and supply chains. Following a theory building approach, authors propose two testable hypotheses for future research.
\end{abstract}

Keywords: Lean, Green, Innovation, Synergies, Case Study 


\section{Introduction}

The growing cost pressure from stakeholders, changes in market conditions, and changes in environmental regulations and laws have forced organisations to rethink beyond economic performance and change their approaches to managing processes and operations that comply with environmental regulations (Cherrafi et al., 2017; Garza-Reyes, 2015; Mollenkopf et al., 2010). The papers that have proposed an integrated approach of lean and green focuses on cost effectiveness of operations through waste reduction and yet meet environmental norms (King \& Lenox, 2001; Larson \& Greenwood, 2004; Franchetti et al., 2009; Carvalho \& Cruz-Machado, 2009; Mollenkopf et al., 2010). Lean thinking aims to reduce TIMWOOD wastes (7 wastes linked to transportation, inventory, motion, waiting, overproduction, over processing, and defects) across operations and supply chain processes to achieve high levels of quality, low costs and short delivery times (Womack \& Jones, 1996; Hines et al., 2004; Kumar et al., 2006; Shah and Ward, 2007; Abdulmalek \& Rojgopal 2007; Dora et al., 2016).

The fast changing nature of the manufacturing industry due to rapid technological advancement, changes in regulations, development of new generation products, and supply, process and demand uncertainty drives organizations to innovate their operations and supply chain processes for environmental improvement rather than creation of environmental values through economic value (Piercy \& Rich, 2015; Ng et al., 2015). Moreover, the new ISO standard, i.e. ISO 9001: 2015, which integrates quality management system (QMS) with environmental management system (EMS), requires organizations to adhere to quality and environmental norms simultaneously (Miguel \& da Fonseca, 2015; Phillips, 2015). 
Contemporary operations management researchers have discussed the synergies and issues in integrating lean operations with green practices, though majority agrees and supports mutually beneficial relationship between lean and green practices (Dües et al., 2013; Martinez-Jurado \& Moyano-Fuentes, 2014; Garza-Reyes, 2015; Ng et al., 2015; Piercy \& Rich, 2015; Garza-Reyes et al., 2016; Tomelero et al., 2017; Cherrafi et al., 2017; Negrao et al., 2017; Colicchia et al., 2017). The integrated approach of lean and green impacts can be achieved by considering environmental value alongside economic value (Figge \& Hahn, 2012); such an approach can lead to reductions in material, product and packaging waste, defects, rework, scrap, energy/water consumption, and pollution costs throughout the supply chain.

It is important to highlight that there is no point in claiming the superiority of one method over other (for example, Florida (1996) and Corbett \& Klasse (2006) claiming green benefits as a by-product of lean). The nature of causation in this scenario is bidirectional and thus organizations need to adopt lean and green principles simultaneously to meet the expectations of the customers and other stakeholders (Carvalho \& Cruz-Machado, 2009; Piercy \& Rich, 2015; Kumar \& Sanchez Rodrigues, 2016). Previous research show that companies that have simultaneously applied lean and green practices have achieved better results than those companies that only focus on either of the initiatives (Negrao et al., 2017; Colicchia et al., 2017; Cherrafi et al., 2017; Ng et al., 2015; Piercy \& Rich, 2015; Kleindorfer et al., 2005).

However, there is still dearth of literature that have investigated synergetic effect of lean and green on innovation practices of an organisation. The joined-up approach of lean and green that shares common objectives and benefits will require a differential approach for addressing economic and environmental values in conjunction. This will 
require innovation in product, processes and organisational structure, for maximising the impact of synergetic application and providing competitive advantage.

Our paper attempts to address this gap by investigating the competitive advantage realised by organisations from the implementation of integrated lean and green practices and how synergetic effects between these two types of practices are achieved through innovation within processes and products. Organisations have three years' transition period (i.e. till 2018) to move from ISO 9001: 2008 to ISO 9001: 2015, which effectively means adopting quality and green practices simultaneously rather than in isolation. This further justifies the need for the application of a holistic leangreen approach in operations and supply chain management. Such an integrated approach forces organisations and employees to innovate their existing methods of operations, processes, and supply chain practices. Innovation in product, process, and supply chains (Lii et al., 2016; Piercy \& Rich, 2015) can enable organisations in the journey of having truly lean-green supply chains.

Resource-based view (RBV) is used as a theoretical lens (Barney, 1991); and, in particular, the concept of complementarity proposed in the realm of RBV (Teece, 1986) is used to achieve the aforementioned objective. RBV focuses on efficient and effective deployment of strategic and valuable resources at the company disposal to drive competitive advantage (Barney et al., 2009; Barney, 1991), whereas the concept of complementarity emphasizes on how one resource influence another resource to affect competitive positions of organisations (Teece, 1986).

This paper attempts to answer the following two research questions:

1) Which are the synergies between lean and green practices?; 
2) How organizations adapt and innovate their operations and supply chain process to synergistically apply lean and green practices?

These research questions are answered by conducting multi-level case studies in a semi-conductor and office furniture manufacturing environment from the UK.

The rest of the paper is structured as follows: section 2 presents a literature review on synergies between lean and green practices and their links to innovation. For the research methodology applied in the study is discussed in section 3 followed by presentation of results in section 4 . Section 5 synthesises the findings from the study and its alignment with previous literature. The paper is concluded in section 6 by highlighting the main contribution of the research and key findings, discussing the managerial implications, limitations of the study and direction for future research.

\section{Theoretical Lens and Background Research}

The first part of the literature review introduces RBV theory and its fit in addressing the two research questions followed by discussion on how the synergetic relationship between lean and green practices is operationalised. Thereafter, the role of innovation

in fostering synergetic relationship between lean and green is discussed. Our study perceive innovation in the similar way as defined by Nicoletti (2015) and Tidd et al. (2005). According to Nicoletti (2015), innovation is defined as both incremental and radical that leads to the introduction of new or improved ways of doing things at work. Tidd et al. (2005, p. 66) describe innovation as "a process of turning opportunity into new ideas and putting these into widely used practice". 


\subsection{Resource-based view}

RBV emphasizes on efficient and effective deployment of valuable, heterogeneous, immobile, and inimitable resources at company's disposal to drive competitive advantage (Khanchanapong et al., 2014; Barney et al., 2009; Hackman and Wageman, 1995; Barney, 1991). Resources can be defined as tangible and intangible assets possessed and controlled by organisations including processes, information systems, knowledge and technologies, among others, to devise and implement strategies that improves its efficiency and effectiveness (Barney, 1991). Organisation can create core competencies by converting the homogeneous and non-rare resources into a process that is heterogeneous and rare for competitors to imitate (Barney and Clark, 2007). The right combination of resources is necessary for achieving sustainable competitive advantage (Ulrich et al., 1995). Individually, lean or green practices can be considered as homogeneous and imitable resources universally acquired by industrial competitors and thus may limit the ability of an organisation to create competitive advantage when applied in an isolation. It has been argued that one resource on its own can never drive sustainable competitive advantage (Enz, 2008).

Organisation need to think of innovative ways of bundling resources that may be difficult for competitors to imitate; and, therefore, resulting in the creation of competitive advantage. In this way, competitors will struggle to assess the manner in which such capabilities were developed. Here, the concept of complementarity proposed by Teece (1986) can be used to explicate how one resource might influence and impact on another, and how this relationship affects competitive positioning or performance of an organisation. In the context of lean and green practices, the synergetic effect of integrated lean and green practices can generate greater value, 
heterogeneity, and improved performance through innovation in design, production and delivery processes (Negrao et al., 2017; Cherrafi et al., 2017; Colicchia et al., 2017; Garza-Reyes et al., 2016; Wiengarten et al., 2013; Yang et al., 2011; Kleindorfer et al., 2005; Florida, 1996). This is because different organisation resources such as lean and green when applied in combination/ simultaneity increases the complexity of resources which competitors may struggle to imitate (Peteraf, 1993); and, at the same time, their synergetic application would drive innovation and deliver enhanced performance than each of them could deliver if implemented in isolation (Negrao et al., 2017; Cherrafi et al., 2017; Garza-Reyes et al., 2016; Piercy and Rich, 2015; Khanchanapong et al., 2014).

The argument is further supported by Ketokivi and Schroeder (2004) and Cua et al (2001), suggesting organisations to create different configurations of basic manufacturing practices for improving in their specific aspects of capabilities and drive competitive advantage. Revisiting Hayes and Wheelwright (1984) four stages model of operations for driving competitive advantage, an organisation can only reach the fourth stage where operation function is externally supportive and influence strategy development and goals of organisations. Here, integrated and joined-up approaches of different manufacturing strategies, including lean and green practices, can help organisation to create innovative processes and products (i.e. jointly impacting on creation of environmental value alongside economic value) that competitors may find difficult to imitate (Baines et al., 2012; Figge and Hahn, 2012; Sarkis et al., 2011; Hart, 1997). 


\subsection{Synergetic relationship between lean and green practices}

The integration of lean and green practices is driven by both internal and external factors (Mollenkopf, et al., 2010). Internal factors driving the lean-green integration include profitability and cost, commodity risk management, and the preservation of a corporate culture (Friedman, 2008; Kleindorfer et al., 2005). External drivers comprises government policies and regulations (Singh et al., 2009), customer and environmental pressures (Negrao et al., 2017; Vachon and Klassen, 2006), a similar focus on continuous innovation and process improvement (Florida, 1996), and the potential for further profitability through added customer value (Kleindorfer et al., 2005). For example, demand uncertainty and non-repetitive production processes characterised by low volume and high variety production would require a different approach to gain greater understanding on synergetic relationship between lean and green practices (Negrao et al., 2017).

The literature on lean and green highlight plenty of similarities between the two practices including waste reduction, waste reduction techniques, lead time reduction, and supplier relationship (Simon \& Mason, 2003; Dües et al., 2013; Piercy \& Rich, 2015; $\mathrm{Ng}$ et al., 2015). Waste reduction in manufacturing operations and/or the supply chain is considered as the key synergy between both practices (King \& Lenox 2001; Mollenkopf et al., 2010; Carvalho et al., 2011; Dües et al., 2013; Garza- Reyes, 2015). The target of reduction in inventory and transportation, the two critical forms of wastes from TIMWOOD category, is also shared by lean and green projects. From a lean perspective, holding excessive inventory increases capital cost and risk of obsolescence. Moreover, certain inventory items require specialised storage such as chilling or controlled environment, which is considered as an environmental waste (Franchetti et al., 2009; Carvalho et al. 2011; Colicchia et al., 2017). Moreover, lean 
and green aim to minimise waste of transportation by reducing the truck miles in order to save cost (lean), reduce $\mathrm{CO}_{2}$ emission (Green), and shorten the lead time of delivery (Colicchia et al., 2017; Garza-Reyes et al., 2016; Carvalho et al., 2011).

At an operational level, incremental or radical improvements in product and process design will improve the life cycle of products and make operations more efficient by reducing the wastes inherent in those processes (Mollenkopf et al., 2010). In terms of supply chain relationships, lean and green aim to achieve close relationship with supply chain partners by providing required training support to improve supplier's capabilities, improving communication across the supply chain and considering suppliers as long-term partners (Cheng et al. 2008; Martinez-Jurado \& MoyanoFuentes, 2014; Piercy \& Rich, 2015; Negrao et al., 2017).

In spite of many common objectives shared between the green and lean, the literature also highlight some misalignments between them (Mollenkopf et al. 2010; Dües et al. 2013; Martinez-Jurado \& Moyano-Fuentes, 2014; Garza-Reyes, 2015). For example, the main focus of lean is cost reduction and flexibility, whereas green is concerned with mitigating the environmental impacts of operations and focuses on sustainable development (Mollenkopf et al. 2010; Dües et al. 2013). Another important divergence between lean and green is around Just-In-Time, in particular, because JIT practice promotes one-piece flow (small lot sizes) which increases frequency of replenishment of raw materials or semi-finished products, thereby increasing the $\mathrm{CO}_{2}$ emissions (King \& Lenox 2001; Dües et al. 2013; Martinez-Jurado \& Moyano-Fuentes, 2014; Garza-Reyes, 2015). Therefore, there is a consensus in the literature that some lean practices can have a negative impact on the environmental performance of operations. However, King \& Lenox (2001) and Dües et al. (2013) claimed that those lean organisations that adopt green practices have better performance than companies 
implementing lean in isolation. This aligns with RBV theory discussion on how integrated approaches to lean and green can make resources complex and unique, so competitors will find difficult to imitate (Khanchanapong et al., 2014). Indeed, Rothenberg et al. (2001) stated that some organisations that adopt lean practices in isolation may not be aware of their environmental risks or may not seek strategically for environmental benefits. Companies may resist adopting green practices because they can be perceived to be time consuming, expensive and their return-on-investment cannot be realised in the short-term (Mollenkopf et al. 2010; Rothenberg et al., 2001).

\subsection{Innovation role in Lean and Green practices}

Companies need to strive for innovation to underline their unique character while increasing their competitive advantage. Utterback (2004) argues that innovation can refer to market positions or paradigms (e.g. business models) and identify the main differences between radical or incremental innovations. According to Blackhurst et al. (2015), innovations are not only restricted to new products through radical innovation but also encompass process improvements across the supply chain. In short, innovations developed for a range of different purposes can be distinguished for their outcomes and characteristics (radical or incremental) and tremendously contribute to the success of a company (Nicoletti, 2015; Sheng \& Chien, 2016).

Chen (2014) specifies green innovation as an organisation's implementation of new ideas, products and processes capable of reducing environmental impacts. The two critical drivers of green innovation are regulations and technological changes (Qi et al., 2010; Triguero et al., 2013; Cuerva et al., 2014; Cai \& Zhou, 2014; Fernando et al., 2015). Following strict environmental regulation will incentivise firms when 
implementing green product innovation (Qi et al.,2010; Triguero et al., 2013), increase its competitive advantage and create an entry barrier for their competitors (Fernando et al. 2015). Technology is another critical factor for green innovation as it plays and an important role in R\&D and production processes by preserving the natural resources and environment (Qi et al. 2010; Cuerva et al. 2014; Fernando et al., 2015). In environmental process innovation, clean technologies can help to reduce wastes and pollution in the whole production process (Triguero et al. 2013).

In an operations management context, environmental product innovation has a positive impact on environmental operational performance in each stage of product lifecycle, because it helps companies to advance the effective use of resource, enhance corporate's image, and comply with environmental regulations (Chen, 2014; Piercy and Rich, 2015). In supply chain context, green supply chain innovation is able to create value by transforming wastes of one organisation to valuable resources of another organisation (Jensen et al., 2013). However, the cost of green innovation may concern some customers as the eco-friendly product are less cost-effective than nonenvironmental products (Triguero et al., 2013; Lin et al., 2014) and not all customers are willing to pay higher prices for green products or services.

The literature indicates that innovation in a lean context is incremental, when applied to R\&D (Gerhard et al., 2012) or production processes (Chen \& Taylor, 2009; Kumar \& Sanchez Rodrigues, 2016; Cherrafi et al., 2017). According to Nicoletti (2015), lean innovation aims to reduce wastes, improve effectiveness, reduce time to introduce new products to market, minimize operating costs, and add value to customers. Similarly, researchers have also reported that an integrated approach to lean and six sigma, termed as lean six sigma, can make the process more effective by improving quality, speed, and reducing production cost, and at the same time, generating positive 
impacts on environmental measures, such as reductions in energy consumption and $\mathrm{CO}_{2}$ emissions (Yudi \& Hiroshi, 2010; Subramanyam et al., 2011; Johnstone et al., 2011; Sony \& Naik, 2012; Cherrafi et al., 2017). When applying lean six sigma to the design process, termed as design for lean six sigma (DFLSS), companies can achieve radical innovation by developing new products or processes that exceeds customer expectations (Yudi \& Hiroshi, 2010; Kumar et al., 2016).

Recent research also identify for misalignment between lean and innovation. For example, lean aims to reduce non-value added time and underutilised design resources (wastes), whereas innovation process requires extra time and resources for the experiment (Chen \& Taylor, 2009). Similarly, lean focuses on mitigating risks at the early stage of production that causes defects and reworks, whereas R\&D process requires to undertake risks during experiments undertaken for new products or process innovation. Chen \& Taylor (2009) also stated that reductions in variability through the application of lean practices can result in high quality at low cost; on the contrary, variability is a key requirement of innovation. Standardization in lean design promotes the use of standard material for production, standard process, and standard parts in designing new products. However, in order to achieve radical innovation, it requires transitional changes in materials and new technical processes and skills (Günther et al. 2008).

Our research will unveil how two selected case companies apply different approaches to drive innovation within operations and supply chain processes through integrated lean and green practices. 


\section{Research methodology}

The empirical rich description of lean and green synergy and their role in supporting innovation can be understood using an inductive theory building approach for conducting exploratory case studies based on theoretical replication logic (Eisenhardt, 1989; Eisenhardt \& Graebner, 2007; Barratt et al., 2011). The strength of case study approach is its ability to offer deep insight and explanation into complex processes that may not be achieved through quantitative methods for data collection (Barratt et al., 2011). Baxter \& Jack (2008) stated that qualitative case study is the best methodology to study the complex and emerging phenomena that allows researchers to derive holistic and meaningful characteristics of organisations and managerial processes.

The case setting of this study are two UK-based manufacturing organizations, a semiconductor manufacturing company (herein called Case $A$ ) and furniture manufacturing company (herein called Case B). The selected cases follow theoretical sampling approach and replication logic proposed by Eisenhardt et al (1989), where each case can be considered as an analytic unit and selected for their fit in illuminating relationships between lean and green practices. Case A and Case B can be considered as 'polar types' and similar from different perspectives. They are similar in their commitment to integrate lean and green practices and have formed crossfunctional teams to maximise the potential benefits realised from the integrated approach. The two cases are polar types when we compare their operations profileCase A operating in high volume/low variety setting, whereas Case B is characterised as low volume and high variety operations. Lean is traditionally applied in high production volume environments; the challenge of applying lean in low production volume/high product variety environments requires different degree of customisation 
and innovation and thus make the two samples interesting to compare. Authors have limited the case sample to two companies for theory building purpose and it also allows for depth of observation and illuminating contrasting patterns in the data (Eisenhardt et al., 1989; Voss et al., 2002; Bartunek et al., 2006).

Twelve semi-structured interviews ( 7 in Case $A$ and 5 in Case $B$ ) were conducted with cross functional team of executives, who are supporting the integration of lean and green practices in the two case organisations. The interviewees in both cases were affiliated to following four departments - production including lean and quality; R \& D; purchasing \& supply chain; and environment and sustainability. The interview protocol used during the data collection was informed by previous literature and was customised as per the position and department of the interviewees. The protocol was piloted with four academics and three practitioners, their comments were used to revise the protocol. The length of each interview varied between 30 minutes to 90 minutes depending upon the positions of the interviewees. Data triangulation was achieved by collating other forms of data including field notes during plant visit and secondary report on lean and green practices published by two selected cases. Data triangulation along with carefully selecting interviewees to get diverse perspectives on lean and green helped in addressing the validity issues encountered in case study research (Yin, 2014).

The reliability of data collected was achieved through the use of case study protocol, involving both authors in each phase namely, conducting interviews, transcription of interview and matching of field notes to draw out the themes, and coding for qualitative data analysis. Table 1 shows demographic details of the two case companies and the roles of interviewees involved in the research. 


\begin{tabular}{|c|c|c|c|c|c|}
\hline Company & $\begin{array}{l}\text { Size of } \\
\text { the } \\
\text { firm }\end{array}$ & $\begin{array}{l}\text { Industry } \\
\text { type }\end{array}$ & $\begin{array}{l}\text { Operations } \\
\text { Profile }\end{array}$ & $\begin{array}{c}\text { No. of } \\
\text { interviews }\end{array}$ & Position \\
\hline Case A & $>500$ & $\begin{array}{l}\text { Semi- } \\
\text { conductor }\end{array}$ & $\begin{array}{c}\text { High } \\
\text { Volume } \\
\text { Low } \\
\text { Variety }\end{array}$ & 7 & $\begin{array}{l}\text { Director of Operations } \\
\text { (IN1) } \\
\text { Lean Manager (IN2) } \\
\text { Quality Director (IN3) } \\
\text { Production Manager (IN4) } \\
\text { Environmental Manager } \\
\text { (IN5) } \\
\text { Purchasing Manager (IN6) } \\
\text { R \& D Manager (IN7) }\end{array}$ \\
\hline Case B & $>500$ & Furniture & $\begin{array}{c}\text { Low } \\
\text { Volume } \\
\text { High } \\
\text { Variety }\end{array}$ & 5 & $\begin{array}{l}\text { Lean Manager (IN8) } \\
\text { Design Team Leader (IN9) } \\
\text { Production manager } \\
\text { (IN10) } \\
\text { Design Engineer (IN11) } \\
\text { Purchasing \& SC manager } \\
\text { (IN12) }\end{array}$ \\
\hline
\end{tabular}

Table 1: Demographic details of case companies

The transcripts were emailed to interviewees for validation of facts and figures and check for any anomaly or misinterpretation of data during the transcription process. The use of protocol helped in conducting thematic analysis of qualitative data, thereby drawing out emerging themes from the data (Miles and Huberman, 1994; Guest et al., 2012). Authors first conducted within case analysis followed by cross-case comparison (Yin, 2014; Eisenhardt et al., 1989) to do pattern matching of key findings emerging from integrated lean and green practices. The analysis of multiple sources of data allowed authors to intertwine the case story with the selected theory, i.e RBV, and demonstrate close link between empirical evidence and emergent theory. Authors have carefully presented the qualitative data in a way that allows to apply and test the concept of complementarity (Teece, 1986) that helps in answering the two research questions. 


\section{Findings}

The first part of the findings section presents the two case companies approaches in integrating lean and green practices and some of the challenges encountered in that process. The second part will report the innovative practices adopted within two companies to simultaneously achieve lean and green objectives.

\subsection{Integration of lean and green practices in case companies}

This section presents the key findings gathered from cases $A$ and $B$ on synergies and misalignments between lean and green practices. Table 2 summarises the key findings obtained from the two cases. The examples cited in Table 2 provide enough evidence to claim for bi-directional/synergetic interaction between lean and green practices. The high volume and low variety production profile in company A, perfect setting for lean and green implementation, allows them to naturally implement integrated lean and green practices. On the contrary, Case B requires customisation in their operating model due to the nature of their operation profile, low volume and high variety production, to implement integrated lean and green practices. All the interviewees in both companies reported limited misalignment between lean and green practices. This also indicate that different internal stakeholders participating in this study were in consensus, according to the data collected from interviews. It is also an indication of how both companies have involved different departments to maximise the benefits obtained from integrating lean and green applications. More information on integration of lean and green practices in each company is discussed in section 4.1.1 and 4.1.2. 


\section{Synergies between lean and green}

\section{Case A}

Driver: Leadership and safety

High production volume and low variety allows the company to apply lean and green practices within shop-floor, design, and supply chain processes.

- The company has conducted several cutting edge integrated lean and green projects such as reduction in energy cost as an example.

- Green projects have helped the firm to save energy cost around £60000 per year.

- Environment and sustainability department interacts with manufacturing department regularly on environmental control measures.

- The team devised new methods of production: 25 wafers per batch is the optimum size for balancing the cost of production and energy consumption.

Work with small suppliers and support them on lean and green measures; difficult to influence large suppliers.

Use of Min-Max inventory model instead of JIT to optimise on cost and green measures

\section{Case B}

Driver: Top management commitment and employee involvement

Make-to-order environment (low production volume and high product variety) of the organisation makes it difficult to apply lean on the shop-floor; lean has been implemented in design process and in the supply chain to improve on green metrics.

The organisation aims to reduce truck miles by separating the geographic area for transportation.

Aims to reduce waste from fabric and try to recycle it as much as possible - this is an example of integrated lean-green project.

\section{Misalignments between lean and green}

There is a contradiction between cycle time metrics (running production line on full load vs. half load) and energy consumption.

Sometimes financial payback on green projects take priority over environmental metrics as environmental project with ROI in less than three years are given priority.
It is difficult to sustain lean practices in maketo-order environment.

Too much focus on measurement can demotivate operator's performance.

Table 2: Synergies and misalignment between lean and green

\subsubsection{Case A: journey towards lean and green integration}

Case A operates three shifts per day to manage approximately forty processes on the production floor. The company started implementing lean in 2011 with the help of training from the Toyota UK improvement team. Lean was implemented as a cost cutting strategy to minimize wastes from their business processes, as company $\mathrm{A}$ faced stiff competition that forced them to reduce their profit margins by squeezing on sales prices. They also implemented an energy management system certification 
ISO50001 that helps them to understand the best practices to minimise energy usage and GHG emissions.

The integration of lean and green practices in Case $A$ is championed by the senior leadership team. The managing director believes in the benefits of a bottom-up approach and provides required support to operators to better manage and innovate their processes. Basic training on lean has been given to all shop-floor operators that has helped the company to sustain benefits from lean by applying lean manufacturing concepts, such as standard work, 5S, suggestion schemes, kaizen, Quality Circles and daily maintenance at the shop-floor level. Since its launch in 2011 , company A has initiated several activities to sustain the lean benefits such as changing the organisation culture (e.g. bottom up approach, shop floor empowerment, investment in education and training) and creating an incentive program to drive intrinsic motivation of employees for continuous improvement. The adoption of lean practices has helped the company to achieve $100 \%$ on-time delivery in the last 44 production weeks of 2016 due to a substantial increase in mechanical and electrical yields, resulting in less wastage of chemicals and wafers, lower energy use and reductions in $\mathrm{CO}_{2}$ emissions.

The environmental engineer (IN5) reported that company A strictly focuses on ISO50001 to better manage its energy consumption as it is one of an important cost category for the company. The company is required to report its energy usage and equivalent tons of $\mathrm{CO} 2$ emitted to meet the existent regulatory compliance set by the UK government for electronics industry. The company has initiated several projects linked to green practices. For example, one specific project on LED replacement has helped company $A$ to save $£ 60000$ in 2016 . Another example of a cutting-edge green project is 'free cooling' which uses the cooling abilities of surrounding environment to 
help modify the temperature of water. Thus, the company is not required to run the chiller and thereby the technology offset the cost of running chiller that uses chemicals and gases. This was the joint lean and green project run between the production and environmental departments. The company is committed to achieving $0 \%$ landfill wastes by 2020 and have managed to achieve 50\% recycling rate; however, Case $\mathrm{A}$ needs to further come up with innovative ideas to achieve $0 \%$ landfill wastes target.

The interviewee IN1 (Operations Director), IN2 (Lean Manager), and IN5 were in consensus that lean and green practices have complementary benefits and their respective departments work together to achieve simultaneously the objective of minimizing waste at shop-floor level and having a greener factory environment. IN5 states that his department normally gives informative feedback regarding environmental control to the manufacturing team. Besides, IN1 mentions that the company is trying to reduce their stock levels in every quarter in order to reduce risk of having unnecessary capital holding and control their inventory by using Min-Max level instead of the more traditional lean practice of 'JIT' delivery, which goes against the principles of green practices. The manufacturing industry in the UK is not suited for JIT practice as the majority of suppliers are based in Europe and other continents, as suggested by IN 1, IN2, and IN6 (Purchasing Manager). The company attempts to use local suppliers, when possible, to minimise their inventory and $\mathrm{CO}_{2}$ emissions generated from the transportation of raw materials from abroad. Case A works closely with small local and foreign suppliers to help them to implement lean and green practices within their companies. However, IN5 stated that it is much easier to have that two-way dialogue and communication when your suppliers are of small size: 
"It is like suppliers are canoes, it is very easy to change the direction if the company is a big ship, but if the company is a canoe and suppliers are big ships and come toward to the firm, this firm is going to be the one who has to change".

(Quote from Environmental Engineer (IN5))

Case A is very environment conscious when it comes to its sourcing strategy. As stated by IN6, the company aims to impact on the environmental performance of its supply chain by sourcing chemicals and gases from suppliers that have recycling process and providing training support to their existing critical suppliers to embed green practices within their operations. This practice is comparable to sourcing strategies applied by Toyota based on having suppliers as partners and improvements achieved at the supply side can result in increased profitability of the whole supply chain.

IN5 stated that misalignment between lean and green is occasionally observed when financial decisions are taken based on relatively short-term payback periods of required investments without considering the benefits of having greener processes or technologies when assessing investment returns in longer time horizons. IN5 stated that they need drive and support from the senior leadership team who works on longterm goals and objectives. Therefore, IN5 suggests that if the company top leader has good environmental and financial awareness, the company could make an argument that lean and green are very aligned, resulting in cost-effective, commercially effective and greener products. Another example of a misalignment between lean and green practices found in company A was highlighted by IN2 and IN4 (Production Manager) in the organisation's cycle time metric that is dependent on the takt time deadline from their customers. To meet the customer delivery deadline, the company has sometimes to run to machines on a half load of its capacity, which is not aligned with green practices. The quote from IN4 encapsulates this specific misalignment: 
"For example, the company aims to run full batch of wafer, 25 wafers per batch for the finishing process in order to save energy consumption, but sometimes they have to put only the half load-in in order to keep line speed instead of waiting, so it can commit with cycle time, but it may not be green".

(Quote from Production Manager (IN4))

\subsubsection{Case B: journey towards lean and green integration}

The operations profile of Case B is low production volume/high product variety in a make to order (MTO) environment. Due to the characteristics of the company, that it is difficult for them to apply comprehensive set of lean tools and techniques on shopfloor. As every furniture order is customised, company B operations need to work in close collaboration with R\&D, sales, purchasing, and environment departments to offset the cost of low volume production and ensure they manufacture eco-design products at the lowest cost and highest quality possible. An interesting analogy to wrestler and dancer was given by IN8 (Lean Manager) that reflects on the high variety of orders received by the company.

"If you are a dancer, you learn the set of a dance routine. The music is played in a particular way and you deploy a set of routines. Conversely, if you are the wrestler, you don't know what is going to come on to you and you have to pre-consider the risk and the potential the things happening, but in effect, you got to be able to change to accommodate to the unexpected. We are more like a wrestler than a dancer."

Quote from Lean Manager (IN8))

The integration of lean and green practices in company $B$ is driven by the senior management team and supported by their four core departments, whose representatives were interviewed during this study. The employees in the company were introduced to some lean practices, including $5 \mathrm{~S}$, quality circle, takt time, and kaizen. Their target of implementing a MTO strategy drives the company to have more agile operations to meet the customer demand on-time and in full. Several root causes 
of wastes in the company is generated by the design and service departments, as stated by IN8 and IN10 (Production Manager). This resulted in shift in focus of lean implementation from shop-floor to these specific departments.

The design team plays a key role in this company to design lean and eco-friendly products, as emphasised by IN9 (Design Team Leader). There are many programs that are currently run by the company to reduce $\mathrm{CO}_{2}$ emission, electricity and gas consumption. The company strictly monitor environmental performance of their suppliers, as stated by IN12 (Purchasing and SC Manager), so they look at where the suppliers buy from, how they are sourcing raw materials and how green the production processes of their suppliers are.

All the interviewees agreed that lean and green simultaneously work towards two goals- waste reduction and improved supply chain relationships. IN8 reported that most of the waste generated in the company comes from the main raw material i.e. fabrics. The company aims to reduce this waste by working with fabric suppliers that take back fabric scrap for reusing within their processes. Moreover, company B also focuses on reducing waste from their transportation by sourcing raw materials from local suppliers. Almost $50 \%$ of all the raw materials they purchase comes from within 10 miles from their factory. Furthermore, the company separates the geographic area for their transportation in order to reduce truck miles. They have also upgraded their trucks to be more efficient in order to reduce $\mathrm{CO}_{2}$ emissions by using Euro 5 compliant engines with higher fuel efficiencies and limiting speed and distance of the trucks.

Another key synergy between lean and green found in Case B is improvement in relationships with their strategic supply chain partners through synergetic application of green and lean practices. Both IN8 and IN9 reports that their design and purchasing 
team work very closely with suppliers that allows JIT delivery, resulting in lower levels of inventories of raw material and finished goods. Moreover, most of company B's suppliers are small firms and are thus more flexible in their approach to accommodate any request from Case B. The company provides strong support to suppliers for enhancing their suppliers' operations capabilities.

The company has ISO 9001:2008 and ISO 14001 certification in place. The requirement to transit to the new version of ISO by 2018 facilitate further integration of lean and green practices, as stated by IN8. None of the interviewees reported any misalignment between lean and green practices.

\subsection{Innovation fostered through lean and green integration}

This section shares examples of incremental innovations demonstrated in Cases $A$ and $B$ as a result of their lean and green practices, as well as a couple of examples of radical innovation in Case $B$. Innovative practices recorded during Case A were found in their manufacturing operations; whereas, in Case B, design department was driving most of the innovative practices. The MTO environment motivated Case B to lean their design process as there were less opportunities of improvements within manufacturing operations. Cross functional collaboration and communication between operations, design, purchasing, environment and sustainability departments facilitated in the integration of lean and green practices in the two companies and planted the seed for incremental innovation. Table 3 summarises the key findings gathered from Cases $A$ and $B$ in their journey towards lean and green integration. More details on innovative practices linked to Cases A and B are provided in section 4.2.1 and 4.2.2. 


\section{Green and Innovation}

\section{Case A}

Driver: Cost and Regulations

The company strictly focuses on ISO 50001

(Energy Management System) which has helped to innovate and embed green practices within shop-floor.

$50 \%$ recycling rate and this also encourages director to perform better; set a target of $0 \%$ wastes going to land fill by 2020 .

Redesign of wafer from 3,000 dices to 6,000 dices helps the firm to be more productive and energy efficient.

The company measure, monitor, and record in term of energy, electricity, gas, and chilling capability.

\section{Case B}

Driver: Regulation, cost, and technology

Engineer product to have a life of 15 years with two periods of complete remanufacture.

Eco-innovation products cost less than nonenvironmental friendly products.

The concept of "Click-Fix" shortens the remanufacturing process time.

The availability of environmental material is one of the major challenge.

\section{Lean and Innovation}

Lean Six Sigma approach help in incremental innovation.

The company get less scrap of wafers because of lean innovation.

Kaizen is used separately in each part of the factory for improving the process, engage the employees, and sustain improvement.

Savings of more than $\$ 1.2$ million from lean six sigma projects that focused on both efficiency improvement and being energy efficient.
Lean helps in incremental and radical innovation, especially within design deptt.. Innovation on new product design can help to reduce waste.

Close relationship with suppliers allow recycling of fabric \& foam waste.

Save $25 \%$ of material used from one design to the new version through lean projects in design.

Table 3: Innovation facilitated through lean and green practice

\subsubsection{Innovative practices in Case $A$}

Case $\mathrm{A}$ has been implementing lean and six sigma for addressing waste and variations issues in their operations. According to the interviewees from Case $A$, company has managed to save over $\$ 1.2$ million from lean six sigma projects since 2011 . IN2 (Lean Manager) claims that continuous improvement culture in their organization is enabled through kaizen and lean six sigma initiatives. Kaizen is applied separately in each area of the company to encourage shop-floor operators to share their innovative ideas for process improvement in particular areas. A suggestion scheme is used by company to empower operators to improve their work area, as well as it helps to improve visibility of operational problems by senior management team, who provides required 
resources from addressing the problem. By applying the bottom-up practice, IN2 states that the company tends to focus on the typical incremental steps of innovation rather than adopting radical improvements. Lean six sigma initiative has helped company A to be innovative and green by reducing wafers' scrap generated from the manufacturing processes. This particular initiative is monitored and facilitated by local improvement teams.

Innovative ideas were also generated after implementation of an ISO50001 certification, which has a primary focus on reducing energy cost. The main green performance element used by company $A$ is reduction in energy consumption across the factory. In terms of innovation, IN7 (R\&D Manager) states that the company is innovation-led and their R\&D team continually generate new processes and technology that can be leaner, greener, more cost effective, and more responsive to customer requirements.

According to IN5 (Environmental Manager), several green innovative projects has been implemented, such as air conditioning management and cooling ability enhancement, which not only help the company to reduce environmental impact, but also save energy cost. For instance, IN5 explained that instead of switching on all air conditioning unit, they are run in sequence from room to room, so cooling generated from the air conditioning units have a faster and more effective effect. This optimise the running of all the air conditioning units and can cut two-third of air conditioning required for the building. Another example of lean and green innovation implemented by the design team that has helped to improve the productivity of the manufacturing process is the redesign of wafers. The new design allowed employees to change the average dices per wafer from 3,000 dices per wafer to 6,000 per wafer, resulting in improvement of economic value alongside environmental value. 


\subsubsection{Innovative practices in Case $B$}

Case B, operating in a low production volume and high product variety environment, adopted a different business model for simultaneous implementation of lean and green practices. Focusing beyond shop-floor operations, Case B have streamlined their design processes through application of lean practices which also improved cross functional teamwork between sales, design, production, purchasing, environment and logistics operations. As stated by IN8, the lean team focuses more on design processes rather than production processes to ensure that the design is right first time and requires less materials compared to previous model. Moreover, IN9 (Design Team Leader) reported that the company usually set the goal of $25 \%$ savings in materials from one design to the new version. Innovation in new product design can help to reduce wastes in the production process. For instance, company has developed an innovative design for new task chairs. This new design allows the company to produce a lighter chair thereby also reducing raw material wastes generated during production process.

The design department is pivotal for enabling the production of innovative and ecofriendly products and thereby providing competitive advantage and a unique selling point against its competitors. Remanufacturing and green design are examples of ecoinnovative practices as reported by the design engineer (IN11) and IN9. These two interviewees reported that Case B is re-engineering their products to have longer life (approximately 15 years) with two periods of complete remanufacturing. After five years, company can take products back and rebuild eco-design products at a $50 \%$ of the cost of original products (i.e. brand new chairs). However, IN9 explains that remanufactured products are not channelled through traditional household markets, instead Case B market remanufactured products for organisations such as home- 
office or other public sector organizations. This also helps public sector organizations to reduce their procurement cost of furniture purchased for their offices.

The company has also partnered with one of their suppliers to recycle rejected and moulded foams which were previously destined to landfill sites. They are working towards the target of 'zero landfill' - annually the company send approximately 65 tonnes to landfill. According to IN9, another new product initiative developed by the design team is called 'click-fit'. This initiative aims to reduce use of materials and make products easy to reassemble, very light and very quick to put it back. It reduces production and assembly time per unit, thereby helping company to reduce operations and environment wastes. The limited availability of environmental friendly raw materials was considered as the main challenge when sourcing scare materials.

\section{Analysis and Synthesis}

\subsection{Lean and Green Practices Integration}

The research question 1 aimed to identify the main synergies in the adoption of lean and green practices in organizations. The complementarity nature of lean and green practices (Teece, 1986) is evident from the analysis of two cases and aligned with findings gathered from the literature review, see table 4. Researchers have highlighted that both lean and green have a common focus of waste reduction at operations and supply level (King \& Lenox 2001; Larson \& Greenwood, 2004; Mollenkopf et al. 2010; Carvalho et al. 2011; Dües et al. 2013; Wiengarten et al., 2013; Khanchanapong et al., 2014; Garza-Reyes, 2015; Ng et al., 2015; Piercy \& Rich, 2015; Cherrafi et al., 2017; Negrao et al., 2017). This finding was equally reported in the two case companies. Case A applied tools such as $5 \mathrm{~S}$, kaizen, quality circles, suggestion 
schemes, and standardised work in combination with ISO50001 to improve productivity, reduce scrap generated from the production process and simultaneously reduce energy consumption across the company. Due to nature of their operations, low production volume and high product variety, Case B applied lean and green practices more in the design stage compared to the production stage to drive design innovation and reduce the usage and level of raw material waste. The fabric suppliers take back the fabric scrap generated by Case B for reusing within their processes.

Researchers claim that minimising level of inventory can reduce capital holding risk, as well as minimise energy consumption in green paradigm (Franchetti et al.,2009; Carvalho et al., 2011; Piercy \& Rich, 2015; Cherrafi et al., 2017). Similar practices were observed during Cases $\mathrm{A}$ and $\mathrm{B}$. Both companies adopt a stock minimisation strategy to reduce physical waste and energy consumption. Case A applies Min-Max method to control inventory instead of the mainstream lean approach of 'JIT' delivery. Carvalho et al. (2011) and Cherrafi et al (2017) states that the objective of both lean and green regarding transportation is to reduce truck miles in order to save cost (a lean metric) and reduce $\mathrm{CO}_{2}$ emissions (a green metric) and also shorten the lead time. Both companies confirmed that having a local sourcing strategy helps to reduce cost, reduce $\mathrm{CO}_{2}$ emissions and enhance the flexibility of their operations. The aforementioned examples illustrate how both companies have managed to create complex resources through the adoption of integrated lean and green practices that competitors will find difficult to imitate. 


\section{Synergy between Lean and Green practices}

\section{Literature}

Focusing on waste reduction

(King and Lenox 2001; Larson \& Greenwood, 2004; Mollenkopf et al. 2010; Carvalho et al. 2011; Dües et al. 2013; Wiengarten et al., 2013; Khanchanapong et al., 2014; GarzaReyes, 2015; Ng et al., 2015; Piercy \& Rich, 2015; Cherrafi et al., 2017)

Minimising inventory level in order to reduce risk on capital holding and energy consumption (Franchetti et al. 2009; Carvalho et al. 2011; Piercy \& Rich, 2015; Cherrafi et al., 2017)

Minimising truck miles in order to save cost, shorten lead time and reduce $\mathrm{CO} 2$ emission (Carvalho et al. 2011; Cherrafi et al., 2017; Colicchia et al., 2017)

Reducing waste through a change in business practice can be done by an adaptation of corporate organisation culture (Mollenkopf et al. 2010; Piercy \& Rich, 2015)

Lean and green aim to have close relationship with supply chain partners because it enables information and best practices of lean and green sharing across the chain (Cheng et al. 2008; Piercy \& Rich, 2015; Negrao et al., 2017)

Transition towards new ISO 9001: 2015 will allow companies to align their quality management system with environment management system (Miguel and da Fonseca, 2015; Phillips, 2015) - leading towards natural alignment between lean and green.

Table 4: Comparison of lean-green synergy from literature and case studies

\section{Supporting findings from Case A \& B}

With lean and green practices, it helps firm to reduce energy consumption within the organisation. (Case A, IN5)

The firm reduces fabric scrap by working with fabric suppliers that take back the scrap for reusing within their process. (Case $B$, IN8)

Trying to reduce inventory level in every quarter in order to reduce risk on capital holding and they control their inventory by using Min-Max level instead of JIT concept. (Case A, IN1)

Case A try to use local suppliers as much as possible to decrease transportation cost.

(Case A, IN1 \& IN6)

This organisation sources supplies locally and almost $50 \%$ of everything they purchase comes from within 10 miles from this factory.

(Case B, IN 8 and 9)

Emphasis on bottom-up approach, employee empowerment and cross functional communication has helped to change the mindset and culture (Case A, IN1)

Worked closely with their suppliers and the suppliers are normally smaller than the company. (Case A, IN5)

Their design team has worked closely with suppliers to reduce inventory, improve communication, and manage fabric design (Case B, IN8,9,11,12)

The new version of ISO helps to simultaneously achieve lean and green objectives (Case B, IN8)

According to Mollenkopf et al. (2010), reducing waste through a change in business practice can be achieved only if organisational culture is considered. Case A emphasize on bottom-up approach, employee empowerment, cross functional communication to manage cultural change in the company since the start of their lean 
journey in 2011. In terms of supply chain relationship, lean and green aim to have close relationship with supply chain partners to share and transfer knowledge linked to innovative company practices (Cheng et al., 2008; Piercy \& Rich, 2015; Negrao et al., 2017). Similarly, IN5 from Case A and IN8 and IN9 from Case B confirmed that their companies have worked closely with their suppliers to reduce inventory level, streamline their supply chain processes and enhance information sharing with their suppliers.

Based on above discussion on synergy between lean and green practices, we observed different set of requirements and practices when organisations have different operations profile such as high/low volume production and high/low variety of products to be manufactured. This requires more investigation and testing in future research and thus one hypothesis to be tested is proposed below.

Hypothesis 1: The degree of synergetic relationship between lean and green is dependent on operation profile of an organisation.

\subsection{Innovative practices to foster lean and green integration}

There was sufficient evidence of innovative practices gathered from Cases A and B that enable both companies to achieve lean and green objectives simultaneously. One of the key observations in both companies that was facilitating innovation activities was formation of cross-functional teams to conduct integrated lean and green projects that resulted in realising economic value alongside environmental value (Wiengarten et al., 2013; Figge \& Hahn, 2012). The change in the organisational structure also improved cross functional communication and knowledge transfer between departments (Piercy \& Rich, 2015; Mollenkopf et al., 2010). Another examples of 
promoting incremental innovation were use of suggestion scheme and Kaizen activities in Case A, that empowered shop-floor employees to improve their processes and also helped senior management to be informed of shop-floor problems and implement corrective changes to make the manufacturing process more green, efficient, cost effective and responsive.

The application of lean and six sigma approach helped Case A to save more than $\$ 1.2$ million by improving on operations and environment metrics such as reduction in scrap, defects, energy usage, $\mathrm{CO}_{2}$ emission, most of the improvement achieved was the result of incremental innovation in process and product design. Researchers have indicated that the adoption of lean and six sigma approaches leads to incremental innovation, and the main outcomes of six sigma implementation are increase in $R \& D$ and production efficiency and reduced time to develop or deliver products to customers (Chen \& Taylor, 2009; Yudi \& Hiroshi, 2010; Gerhard et al., 2012; Antony et al., 2014; Nicoletti, 2015; Kumar et al., 2016).

Case $A$ also reported reduction in wafers scrap through the application of an integrated lean and six sigma approach that improved productivity and reduced energy cost. Cherrafi et al. (2017) found that the integrated lean six sigma approach can help organisations to achieve superior sustainability performance. Similarly, Subramanyam et al. (2011) and Johnstone et al. (2011) state that implementing lean six sigma can foster innovation; and, as a result, improve quality, speed, cost, and at the same time, compress the time to market new products. The lean manager (IN8) and design team leader (IN9) from Case B concurred that innovation in new product design through adoption of a lean approach, similar to approach proposed by Larson \& Greenwood (2004), also helped Case B to get design right first time and reduce waste from the production process by saving $25 \%$ use of materials from one design to the new 
version. Compared to Case A, where lean activities were mostly focused in production area, Case B had to customize their lean implementation due to low volume and high variety operations and shift the focus of implementation from production to design and service delivery processes. This is another example from RBV perspectives on how organisation create complex resources through adaption of processes, products, and organisational structure that promotes innovation within the workplace and provide competitive advantages over their competitors. Though the literature has reported few misalignments between innovation and lean, for example, Chen \& Taylor (2009) state that lean principle aims to reduce non-value added time and underutilised design resources (waste), whereas innovation requires extra time and resources for experiments), there were no statement given by interviewees from Cases $A$ and $B$ regarding the misalignment between innovation and lean.

Chen et al. (2006) states that green innovation can increase the competitiveness of firms by allowing companies to differentiate their products and expand or enter new market. Moreover, Chen (2014) claims that green innovation helps companies to improve resource efficiency, enhance corporate's image, and comply with environmental regulations. Example from Case $A$ confirmed that the redesigned wafers simultaneously helped to achieve lean and green objectives, i.e., changing the average dices per wafer from 3,000 dices per wafer to 6,000 per wafer and this helped the company to have more efficient outputs with less usage of energy, and improved their competitiveness in the market. Another example cited by IN5 from Case A shows how green innovation impact on equipment/machine efficiency, i.e. air conditioning management and use of chiller are good examples of effective use of resource (see section 4.1.1). The design team leader (IN9) from Case B also had similar view point that green innovation has helped their company to expand to new market like 
remanufacturing market. Both companies have developed their own customised synergetic lean and green practices that fosters innovation within operations and supply chain processes, resulting in sustained competitive advantage.

Green supply chain innovation enables to create value by transforming wastes of one organisation to valuable resources for another organisation (Jensen et al. 2013). Example of this includes passing on the scrap fabrics and wasted foams by Case $B$ to suppliers for reuse in their production process. Similarly, Case A attempts to adopt a green sourcing strategy by purchasing chemical or gas from suppliers which have recycling process or setting and running a customised training program to enable their managers and other employees to embed environmental practices in supplier's operations. Considering suppliers as partners and supporting them to improve their capabilities is one of the basic tenets of lean supply chain management as well (Hines et al., 2004; Shah \& Ward, 2007; Piercy \& Rich, 2015; Negrao et al., 2017).

Recent research claims that green product innovation may be less cost-effective than non-environmental products and not all customers are willing to pay high price for green products or services (Triguero et al.,2013; Lin et al., 2014). On the contrary, the case findings report that eco-design products can be less costly than normal products, if the design / R\&D process is leaned. IN8 and IN9 from Case B argued that the production cost of eco-design products, e.g. remanufactured chairs, cost $50 \%$ less than normal products or new chairs. Similarly, the design of eco-friendly processes through the adoption of lean-green innovative practices found in Case A resulted in improved productivity, low operational cost and significant reductions in energy cost to the company. 


\section{Innovative practices through lean and green practices}

\section{Literature}

Lean principle has positive impact on incremental innovation in term of increasing $R \& D$ efficiency, production efficiency and reducing $R \& D$ time or delivery time to customer. (Chen \& Taylor, 2009; Yudi \& Hiroshi, 2010; Gerhard et al., 2012; Antony et al., 2014; Nicoletti,2015; Kumar et al., 2016)

\section{Supporting findings from Case A \& B}

The suggestion scheme, which linked to Kaizen, not only makes operator's life easier, but it also helps senior management to know issues, changes the processes, and be more efficient, cost effective, and faster. (Case A, IN1 and 4)

Lean process and innovation help the organisation to reduce scraps of wafers from the process. (Case A, IN3)

Innovation on new product design can help to reduce wastes in the production process by saving $25 \%$ use of material from one design to the new version. (Case B, IN8)

The combined approach of lean six sigma foster innovation and superior sustainability performance by improving quality, speed, and cost. Yudi and Hiroshi 2010;

Subramanyam et al. 2011; Johnstone et al. 2011; Antony et al., 2014; Cheraffi et al., 2017)

\section{Green innovation can increase competitiveness of firms by allowing companies to differentiate their products and expand or enter to new market (Chen et al. 2006) or advance effective use of resource and comply with environmental regulations (Chen 2014).}

Lean Six Sigma helps the company to save $\$ 1.2$ million in total including improvement economic and environmental metrics. (Case A, IN1 and 3)

The company tends to focus on incremental steps of improvement rather than radical improvement as they change the processes based on their operator's suggestions (Case A, IN2)

Lean is implemented with the design team in order to ensure that the design will get right first time, thereby impacting on productivity, reduced usage of scare resources,

(Case B, IN8)

Integrated lean \& green practices has helped to redesign wafers resulting in changing the average dices per wafer from 3,000 dices per wafer to 6,000 per wafer. (Case A, IN1)

The air conditioning management project is a good example of the effective use of resource and green innovative practice. (Case A, Interviewee E)

Green innovation is about what engineer can do with the design and it gives lots of competitive advantage to the organisation. (Case B, IN9 and 11)

Lean and Green innovation helps the company to expand to new market like remanufacturing market.

(Case B, IN8) 
Green supply chain innovation is able to create value by transforming wastes of one organisation to valuable resources of another organisation. (Jensen et al. 2013)
Passing on the scrap fabrics and wasted foams to suppliers for reuse in their production process. (Case B, IN9)

Sourcing chemical or gas from suppliers having recycling process \& encourage/ provide training support to their suppliers to embed environmental practices. (Case A, IN6)

Table 5: Innovative practices through lean and green practices

The discussion linked to innovation as an outcome of synergetic application of lean and green practices require further validation and testing through future research. Another hypothesis emerging from the discussion that requires further testing is:

Hypothesis 2: The synergetic effect of lean and green practices on innovation is dependent on operation profile of an organisation.

\section{Conclusions}

The case studies conducted in the two UK manufacturing organisations adopting RBV theoretical lens (and in particular concept of complementarity) have illustrated how organisations create heterogeneous and unique resources through adaption in their structure, processes, and products that results in sustainable competitive advantage over their competitors (Barney, 1991). The concept of complementarity (Teece, 1986) was further tested and validated through two cases by providing examples of activities to qualitatively test the synergetic relationship between lean and green practices and how innovation is fostered through synergetic lean and green applications (Wiengarten et al., 2013; Piercy \& Rich, 2015; Ng et al., 2015; Garza-Reyes et al., 2016; Cherrafi et al., 2017). This exploratory study is among very few studies that discuss the role of innovation in lean and green contexts. It is important to understand the profile of operations, e.g. high production volume/low production variety vs low production 
volume/high product variety, as it can affect the degree of customisation of organisational processes and structure required to facilitate integrated lean-green practices in an organization. The interviewees in both case companies confirmed that waste reduction and close relationships with suppliers can help to achieve both lean and green objectives (Dues et al., 2013; Piercy \& Rich, 2015; Garza-Reyes, 2015). Interviewees from Cases $A$ and $B$ agreed that that top management commitment, cost reduction, and safety are the main drivers of lean-green projects ( $\mathrm{Ng}$ et al., 2015; Cherrafi et al., 2017; Piercy \& Rich 2015).

There were several examples of innovative practices adopted by the two case companies as a result of pursuing their lean and green journeys. The interviewees confirmed that green innovations not only help their company to enhance their competitiveness and expand to new markets, but it also facilitates minimal use of organisational resources for enhancing efficiency and environmental values simultaneously (Figge \& Hahn, 2012). This finding is aligned with evidence from previous research studies (Chang \& Chen, 2013; Triguero et al., 2013; Cai \& Zhou, 2014; Qi et al., 2010). One of the interesting findings gathered from the case studies that differs from the literature (Triguero et al., 2013; Lin et al., 2014) is that the production cost of environmentally friendly products can decrease if organisation is ready to be lean and innovative within their $R$ \& $D$ processes. Evidence gathered from the case studies also supported the claim in the literature that lean six sigma practices can foster incremental innovation in organisations (Cherrafi et al., 2017; Subramanyam et al., 2011; Johnston et al., 2011; Yudi \& Hiroshi, 2010).

Various managerial implications were identified as the result of this research. The key driver for achieving synergy between lean and green practices is the support from senior management who has willingness to invest in human capital resources and 
technology and are patient enough to wait for financial payback. Managers should not treat lean and green in isolation. Apart from getting support from the senior management team, it is important to break the shell of functionality and form crossfunctional teams to promote process and product innovation as demonstrated in two case. Both Cases A and B formed cross-functional teams before developing implementation strategy for integrating lean and green practices. Managers also need to reflect on alignment of metrics used to individually report lean and green practices. Both sets of metrics should positively align and help drive innovation in the workplace. The real benefit of integrated lean and green practices can be realised when cross functional team across the organisational boundaries work together from design to product delivery to after sales services. Gaining understanding of nature of operations, market conditions and supply chain environment can help managers to customise their lean and green practices to suit their company requirement instead of copying traditional lean and green models applied in other organisations.

In spite of several interesting findings derived from this study, like any other research, it has also got its opportunities of further research. In order to build on the two contrasting case studies presented in the paper, a large-scale questionnaireinstrument can be used to survey a larger sample of operations from a wider range of sectors and countries to test the two hypothesis proposed in the discussion section. This will help to test the validity of the findings in a wider range of settings, by including factors that influence green and lean performance, such as organisation maturity, culture and size, supply side, sector, product characteristics, customer and geographical context. Furthermore, action research can be undertaken to gain greater understanding of the impact of particular innovations and the influence of particular success factors and barriers affecting green-lean projects, including a wide range of 
stakeholders such as suppliers, the manufacturer, service providers and policy

makers. The exploratory study using two case examples can be treated as pilot and future research will also pursue some of the aforementioned research avenues through deductive enquiry.

\section{References}

Abdulmalek, F.A. and Rojgopal, J. 2007. Analysing the benefits of lean manufacturing and value stream mapping via simulation: A process sector case study. International Journal of Production Economics, 107(1), 223-236.

Antony, J., Setijono,D.,\& Kumar, M. 2012. Can Lean Six Sigma lead to Process Innovation? An exploratory research. 1st-5th July 2012, 4th World P\&OM Conference/19th International Annual EurOMA Conference, Amsterdam, Netherlands.

Baines, T., Brown, S., Benedettini, O., \& Ball, P. 2012. Examining green production and its role within the competitive strategy of manufacturers. Journal of Industrial Engineering and Management, 5(1), 53-87.

Barney, J. 1991. Firm Resources and Sustained Competitive Advantage (Anonymous, eds). Journal of Management, 17 (1), 99-120.

Barney, J. B., \& Clark, D. N. 2007. Resource-based theory: creating and sustaining competitive advantage, Oxford University Press, Oxford.

Barney, J., Wright, M. \& Ketchen, D.J.J. 2009. The Resource Based View of the Firm: Ten Years after 1991. Journal of Management, 27(6), 625-641.

Barratt, M., Choi, T.Y., Li, Mei. 2011. Qualitative case studies in operations management: Trends, research outcomes, and future research implications. Journal of Operations Management, 29, 329-342.

Bartunek, J.M., Rynes, S.L., and Ireland, R.D. 2006. What makes management research interesting and why does it matter? Academy of Management Journal, 49, 9-15.

Baxter, P., \& Jack, S. (2008). Qualitative Case Study Methodology: Study Design and Implementation for Novice Researchers. The Qualitative Report, 13(4), 544-559.

Blackhurst, J., Manhart, P. and Kohnke, E. 2015. The five key components for supply chain innovation. Supply Chain Management Review 19(2), 10-16.

Cai, W.G. and Zhou, X.L. 2014. On the drivers of eco-innovation: empirical evidence from China. Journal of Cleaner Production, 79, 239-248.

Carvalho, H., \& V. Cruz-Machado. 2009. Lean, Agile, Resilient and Green Supply Chain: A Review. In Proceedings of the Third International Conference on Management Science and Engineering Management, 3-14. Bangkok

Carvalho, H., Duarte, S., \& Cruz-Machado, V. 2011. Lean, agile, resilient and green: divergencies and synergies. International Journal of Lean Six Sigma, 2(2), 151179.

Chang, C.H. \& Chen, Y.S. 2013. Green organizational identity and green innovation. Management Decision, 51(5), 1056-1070. 
Chang,C.H. \& Chen, Y. S. 2013. Green Organizational Identity and Green Innovation.Management Decision, 51( 5), 1056 - 1070.

Chen, H. \& Taylor, D. 2009. Exploring the impact of lean management on innovation capability. PICMET '09 - 2009 Portland International Conference on Management of Engineering \& Technology, Portland, USA, 826-834.

Chen, R.H. 2014. Effects of Green Operations and Green Innovation on Firm's Environmental Performance. Industrial Engineering \& Management Systems 13(2), 118-128.

Cheng, J.-H., Yeh, C.-H., Tu, C.-W., 2008. Trust and knowledge sharing in green supply chains. Supply Chain Management: An International Journal, 13(4), 283295.

Cherrafi, A., Elfezazi, S., Govindan, K., Garza-Reyes,J.A., Benhida, K., \& Mokhlis, A., 2017. A framework for the integration of Green and Lean Six Sigma for superior sustainability performance. International Journal of Production Research, 55(15), 4481-4515.

Colicchia, C., Creazza, A., \& Dallari, F., 2017. Lean and green supply chain management through intermodal transport: insights from the fast moving consumer goods industry. Production Planning \& Control - The Management of Operations, 28 (4), 1221-1232.

Corbett, C.J. \& Klassen, R.D. 2006. Extending the horizons: environmental excellence as key to improving operations. Manufacturing and Service Operations Management, 8(1), 5-22.

Cua, K. O., McKone, K. E., \& Schroeder,R. G., 2001. Relationships between implementation of TQM, JIT, and TPM and manufacturing performance. Journal of Operations Management, 19(6),675-694.

Cuerva, M.C., Triguero-Cano, A., \& Córcoles, D., 2014. Drivers of green and nongreen innovation: empirical evidence in Low-Tech SMEs. Journal of Cleaner Production, 68(4), 104-113.

Dora, M., Kumar,M., Gellynck, X. 2016. Determinants and Barriers to Lean Implementation in Food Processing SMEs- A Multiple Case Analysis. Production Planning \& Control: The Management of Operations, 27(1), 1-23.

Dües, C.M., Tan, K. H., \& Lim, M., 2013. Green as the new Lean: how to use Lean practices as a catalyst to greening your supply chain. Journal of Cleaner Production, 40, 93-100.

Eisenhardt, K.M. 1989. Building Theories from Case Study research. Academy of Management Review, 14(4), 532-550.

Eisenhardt, K.M., and Graebner, M.E., 2007. Theory Building from cases: opportunities and challenges. Academy of Management Journal, 50(1), 25-32.

Enz, C. A 2008. Creating a Competitive Advantage by Building Resource Capability: The Case of Outback Steakhouse Korea. Cornell Hospitality Quarterly, 49(1), 7378.

Fernando, Y., Wah, W.X., Shaharudin, M.S. 2016. Does a firm's innovation category matter in practising eco-innovation? Evidence from the lens of Malaysia companies practicing green technology. Journal of Manufacturing Technology Management, 27(2), 208-233.

Figge, F., \& Hahn, T., 2012. Is green and profitable sustainable? Assessing the tradeoff between economic and environmental aspects. International Journal of Production Economics, 140, 92-102.

Florida, R. 1996. Lean and Green: The Move to Environmentally Conscious Manufacturing. California Management Review, 39(1), 80-105. 
Franchetti, M., Bedal, K., Ulloa, J., Grodek, S., 2009. Industrial engineering methods are natural stepping stones to green engineering. Industrial Engineering, 24-30.

Garza-Reyes, J., Villarreal, B., Kumar, V., \& Molina Ruiz, P., 2016. Lean and green in the transport and logistics sector - a case study of simultaneous deployment. Production Planning \& Control - The Management of Operations, 27 (15), 1221 1232.

Garza-Reyes, J.A. 2015. Lean and green - a systematic review of the state of the art literature. Journal of Cleaner Production 102, pp.18-29.

Gerhard, D., Engel,S., Scheiner, C., Voig, K-I. 2012.The application of lean principles and its effects in technology development. International Journal of Technology Management, 57(1-3), 92-109.

Guest, G., MacQueen, K. M., Namey, E.E. 2012. Applied Thematic Analysis. Thousand Oaks, CA: Sage Publications Inc.

Günther, S. et al. 2008. Lean innovation: introducing value systems to product development. PICMET '09 - 2009 Portland International Conference on Management of Engineering \& Technology, Cape Town, South Africa, 11291136.

Hackman,J.R., \& Wageman,R.,1995.Total quality management: empirical, conceptual, and practical issues. Administrative Science Quarterly, 40(2),309342.

Hart, S. 1997. Beyond greening: strategies for a sustainable world. Harvard Business Review, January-February, 66 - 77.

Hines, P., Holweg, M., Rich, N., 2004. Learning to evolve: a review of contemporary lean thinking. International Journal of Operations and Production Management, 24(10), 994-1011.

Jensen, J. K., Munksgaard, K.B., Arlbjørn, J.S. 2013. Chasing value offerings through Green supply chain innovation. European Business Review 25(2), 124-146.

Johnstone, C., Pairaudeau, G., Pettersson, J.A. 2011. Creativity, innovation and lean sigma: a controversial combination?. Drug Discovery Today, 16(1-2), 50-57.

Ketokivi,M. A., Schroeder, R.G., 2004. Perceptual measures of performance: fact or fiction? Journal of Operations Management, 22(3), 247-264.

Khanchanapong, T., Prajogo,D., Sohal, A.S., Cooper,B.K., Yeung, A.C.L., \& Cheng,T.C.E. 2014. The unique and complementary effects of manufacturing technologies and lean practices on manufacturing operational performance. International Journal of Production Economics, 153(), 191-203.

King, A.A., Lenox, M.J., 2001. Lean and green? an empirical examination of the relationship between lean production and environmental performance. Production and Operations Management, 10 (3), 244-256.

Kleindorfer, P.R. Singhal, K., \& Van Wassenhove,L.N. 2005. Sustainable Operations Management. Production and Operations Management, 14(4), 482-492.

Kumar, M., \& Rodrigues, V.S. 2016. Lean Green and Innovation: Synergies and Misalignment. 6th-9th May 2016, 2016 POMS Annual Conference, Orlando, Florida, USA.

Kumar, M., Antony, J., Singh, R.K., Tiwari, M.K., \& Perry, D. 2006. Implementing the Lean Sigma Framework in an Indian SME: A Case Study. Production Planning and Control. 17(4), 407-423.

Kumar, S., Luthra,S., Govindan, K., Kumar, N., \& Haleem, A.. 2016. Barriers in green lean six sigma product development process: an ISM approach. Production Planning \& Control. 27(7-8), 604-620. 
Larson, T., \& Greenwood, R. 2004. Perfect complements: Synergies between lean production and eco-sustainability initiatives. Environmental Quality Management, 13(4), 27-36.

$\mathrm{Li}, \mathrm{S}$. \& Ni, J. 2016. A dynamic analysis of investment in process and product innovation with learning-by-doing. Economics Letters, 145, 104-108.

Liker, J.K. 2004. The Toyota Way: 14 Management Principles from the World's Greatest Manufacturer. New York: McGraw-Hill.

Lin, R-J., Chen, R-H., \& Huang, F-H. 2014. Green innovation in the automobile industry. Industrial Management \& Data Systems, 114(6), 886-903.

Martinez-Jurado, P.J. and Moyano-Fuentes, J. 2014. Lean Management, Supply Chain Management and Sustainability: A Literature Review. Journal of Cleaner Production, 8(5), 134-150.

Meridith, J.R., 1998. Building operations management theory through case and field research. Journal of Operations Management, 16(4), 439-452.

Miguel, L., \& da Fonseca, C.M. 2015. ISO 14001:2015: An Improved Tool for Sustainability. Journal of Industrial Engineering and Management 8(1): 37-50

Miles, M.B., and Huberman, A.M., 1994. Qualitative data analysis: an expanded sourcebook. Thousand Oaks, CA: Sage Publications Inc.

Mollenkopf, D., Stolze, H., Tate, W., \& Ueltschy, M. 2010. Green, lean, and global supply chains. International Journal of Physical Distribution \& Logistics Management, 40(1/2), 14-41.

Negrao, L.L.L., Filho, M.G., and Marodin, G. 2017. Lean practices and their effect on performance: a literature review. Production Planning \& Control- - The Management of Operations, 28(1), 33-56.

Ng,R., Low, J.S.C., \& Song, B. 2015. Integrating and implementing Lean and Green practices based on proposition of Carbon-Value Efficiency metric. Journal of Cleaner Production, 95, 242-255.

Nicoletti, B. 2015. Optimizing Innovation with the Lean and Digitize Innovation Process. Technology Innovation Management Review, 5(3), 29-38.

Peteraf, M.A. 1993. The Cornerstones of Competitive Advantage: A Resource-Based View. Strategic Management Journal, 14(3), 179-191.

Philipps, A.W., 2015. ISO9001:2015 Internal Audits Made Easy: Tools, Techniques, and Step-By-Step Guidelines for Successful Internal Audits. $4^{\text {th }}$ edition, Wisconsin: ASQ Quality Press.

Piercy, N., \& Rich, N. 2015. The relationship between lean operations and sustainable operations. International Journal of Operations and Production Management, 35(2), 282-315.

Porter, M.E. 1985. Competitive Advantage. Strategic Management, May-June, 1-580.

Qi, G.Y. Shen, L.Y., Zeng, S.X., \& Jorge, O.J. 2010. The drivers for contractors' green innovation: an industry perspective. Journal of Cleaner Production, 18(14), 13581365.

Rothenberg, S., Pil, F. K., \& Maxwell, J. 2001. Lean, Green, and the Quest for Superior Environmental Performance. Production and Operations Management, 10(3), 228-243.

Sarkis, J., Zhu,Q., Lai, K-H. 2011. An organizational theoretic review of green supply chain management literature. International Journal of Production Economics, 130, 1-15.

Shah, R., \& Ward, P.T. 2007. Defining and developing measures of lean production. Journal of Operations Management, 25, 785-805. 
Sheng, M.L. and Chien, I. 2016. Rethinking organizational learning orientation on radical and incremental innovation in high-tech firms. Journal of Business Research, 69(6), 2302-2308.

Simons, D. \& Mason, R. 2013. Lean and Green: 'doing more with less'. International Commerce Review: ECR Journal (3)1, 84-91.

Singh, B., Garg, S.K. \& Sharma, S.K., 2009. Reflective Practice: Lean can be a survival strategy during recessionary times. International Journal of Productivity and Performance Management, 58 (8), 803-808.

Sony, M. and Naik, S. 2012. Six Sigma, organizational learning and innovation: An integration and empirical examination. International Journal of Quality \& Reliability Management, 29(8), 915-936.

Subramaniyam, P., Srinivasan, K., \& Prabaharan, M. 2011. An Innovative Lean Six Sigma Approach for Engineering Design. International Journal of Innovation Management and Technology, 2(2), 166-170.

Teece, D.J. 1986. Firm boundaries, technological innovation and strategic planning, in Thomas, G.L. (Ed.), The Economics of Strategic Planning, D.C., Heath, Lexington, MA, pp. 187-99.

Tidd, J., Bessant, J. and Pavitt, K. 2005. Managing innovation: Integrating technological, market and organizational change. 3rd edition. John Wiley \& Sons.

Tomelero,R.L., Ferreira, J.C.E., Kumar, V., \& Garza-Reyes, J.A. 2017. A lean environmental benchmarking (LEB) method for the management of cutting tools. International Journal of Production Research, 55(13), 3788-3807.

Triguero, A., Moreno-Mondéjar, L., Davia, M.A. 2013. Drivers of different types of ecoinnovation in European SMEs. Ecological Economics, 92, 25-33.

Ulrich, D. Brockbank,W., Yeung, A.K., Lake, D.G., 1995. Human Resource Competencies: An Empirical Assessment. Human Resource Management, 34 (4), 473-495.

Utterback, J.M. 2004. Mastering the Dynamics of Innovation, $2^{\text {nd }}$ edition, Boston, Mass.: Harvard University Business School Press.

Vachon, S., \& Klassen, R.D. 2006. Extending green practices across the supply chain: The impact of upstream and downstream integration. International Journal of Operations \& Production Management, 26 (7), 795-821.

Voss, C.A., Tsikriktsis, N., Frohlich, M., 2002. Case research in operations management. Journal of Operations Management, 22, 195-219.

Wiengarten, F., Fynes, B., \& Onofrei, G. 2013. Exploring synergetic effects between investments in environmental and quality/lean practices in supply chains. Supply Chain Management: An International Journal, 18(2), 148-160.

Womack, J.P. and Jones, D.T. 1996. Beyond Toyota: How to Root Out Waste and Pursue Perfection. Harvard Business Review, September-October 1996, 140158.

Yin, R.K. 2014. Case Study research: Design and methods. $5^{\text {th }}$ edition, Thousand Oaks, CA: Sage Publications Inc.

Yudi, A. \& Hiroshi, O. 2010. Innovation in management system by Six Sigma: an empirical study of world-class companies. International Journal of Lean Six Sigma, 1(3), 172-190. 